\title{
Body fat and aerobic capacity of physical education students from a Chilean university
}

\author{
Jorge Mendez-Cornejo (1), Ruben Vidal Espinoza (2), Gernot Hecht Chau (3), Camilo \\ Urra Albornoz (4), Rossana Gomez-Campos (5), Marco Cossio-Bolaños (1)
}

(1) Departamento de Ciencias de la Actividad Física, Universidad Católica del Maule, Talca, Chile; (2) Universidad Católica Silva Henriquez, Santiago, Chile; (3) Universidad Técnica Federico Santa María, Valparaiso, Chile; (4) Escuela de Ciencias del Deporte y Actividad Fïsica, Facultad de Salud, Universidad Santo Tomás, Chile; (5) Departamento de Diversidad e Inclusividad Educativa, Universidad Católica del Maule, Talca, Chile.

This article is distributed under the terms of the Creative Commons Attribution Noncommercial License (CC BY-NC 4.0) which permits any noncommercial use, distribution, and reproduction in any medium, provided the original author(s) and source are credited.

\begin{abstract}
The components of physical fitness, aerobic capacity and anthropometric characteristics play an important role in maintaining and protecting cardiorespiratory functioning during all stages of life. The purpose of this study was to analyze the relationship between body fat indicators and aerobic capacity of students in a physical education program. A descriptive study (crosssectional) was carried out with 110 physical education university students (75 males and 35 females). Ages ranged between 17.7 and 26.1 years old. Weight, standing height, sitting height, waist circumference (WC), and seven skinfolds (mm) were evaluated. Body Mass Index (BMI) was calculated. The Navette test (20m back and forth run) was used to assess the students. The correlations between adiposity and aerobic capacity for males varied from $\mathrm{r}=-0.21$ to 0.34 and for females, from $\mathrm{r}=-0.21$ to 0.34 . In general, greater body adiposity (BMI, WC, and skinfolds) was a determinant in the males ( $\mathrm{R} 2=14$ to $27 \%$ ). For the females, the $\Sigma 7$ skinfolds explained $11 \%$ of the adiposity. Males and females classified as having a high level of aerobic capacity showed less fat tissue ( $\Sigma 7$ skinfolds) than those with moderate and low aerobic capacity $(\mathrm{p}<0.05)$. The results from this study indicated that body adiposity expressed as fat tissue limited aerobic capacity in a greater proportion of the males than in the females. The youth classified with high aerobic capacity showed less body fat than their counterparts classified as having moderate and low levels of aerobic capacity.
\end{abstract}

Key Words: Aerobic capacity; body adiposity; physical education; university students.

Eur J Transl Myol 31 (4): 10031, 2021 doi: 10.4081/ejtm.2021.10031

In Chile and throughout the world, obesity is a prevalent chronic illness. It is characterized by the presence of high levels of fat tissue. In general, it is widely known that overweight and obesity have a significant impact on the physical and psychological health of children, youth and adults, and they are more likely to develop noncommunicable diseases such as diabetes and cardiovascular disease at a younger age. The presence of these factors influence life expectancy and quality of life of individuals. ${ }^{1}$ According to the World Health Organization (WHO), ${ }^{2}$ since 1975, obesity has tripled around the world. For example, a minimum of 2.8 million people die each year due to obesity and overweight. In Chile, during the past few years, body adiposity has been increasing in young university students. ${ }^{3}$ This appears to be the result of the lack of physical activity and an unhealthy sedentary lifestyle that limit the levels of physical fitness. In fact, studies have shown that a high level of physical fitness at early ages is associated negatively with obesity, cardiovascular diseases, skeletal health, and mental health. ${ }^{4-6}$ At more advanced ages, these populations are not able to develop acceptable levels of physical fitness in their daily activities. In this sense, a high level of physical fitness at early ages is negatively associated with obesity, cardiovascular diseases play an important role in maintaining and protecting cardiorespiratory functioning during all stages of life. Therefore, high levels of maximum oxygen consumption and satisfactory \% values of body fat in the young guarantee an acceptable level of physical performance and, consequently, a healthy life. ${ }^{7,8}$ From this perspective, this research was based on a number of studies that demonstrated that excess body adiposity 


\section{Body fat and aerobic capacity of physical education students}

Eur J Transl Myol 31 (4): 10031, 2021 doi: 10.4081/ejtm.2021.10031

limits maximum oxygen consumption in sedentary populations, ${ }^{9}$ where the percentage of body fat is closely related to hypertension and other metabolic illnesses. ${ }^{10}$ However information is scare about the distribution of fat tissue where, probably, a higher level of body adiposity may reflect a lower aerobic capacity, especially in physical education students. Thus, it is well known that physical education students, in general, are in constant movement and participating in physical sports activities compared to other groups of young university students. The rationale for studying a group of normal weight physical education students, with a relatively higher physical capacity as compared to a normal youth population, may help provide information about factors related to a sedentary lifestyle. In fact, it is widely accepted that regular physical activity plays an important role in maintaining body weight and body composition as well as regulating the muscle skeletal metabolism and fat tissue. ${ }^{9}$ Thus, the objective of this study was to analyze the relationship between the body adiposity indicators and the aerobic capacity of students from a physical education program.

\section{Materials and Methods}

A descriptive (cross-sectional) study was carried out with 110 university students (75 males and 35 females) from a physical education program in the Maule Region of Chile. Students' ages ranged from 17.7 to 26.1 years old.
The sample was selected by convenience in a nonprobabilistic way. These young students of a physical education program attended a university in Talca and performed moderate intensity physical activity twice a week 90min/day. These activities were part of the physical education students' sports subjects. The students included in the study were those with a normal Body Mass Index and those who were 18 years old. Students who did not complete the anthropometric evaluations or the physical test were excluded. The research related to human use has been complied with all relevant national regulations and institutional policies, has followed the tenets of the Declaration of Helsinki, and has been approved by the authors' institutional ethics committee. The young people in the study authorized and signed the informed consent to voluntarily participate in the study. Variables, such as birth date and sex, were collected from the registration records from the physical education program at the university. Anthropometric variables were measured based on the descriptions provided by Ross and Marfell-Jones. ${ }^{11}$ All anthropometric variables were measured in the laboratory of the local university where the study was conducted. Body weight (kg) was determined by using an electronic scale (Tanita, United Kingdom, Ltd) with a scale of 0-150 kg and an accuracy of $100 \mathrm{~g}$. Standing height and sitting height were measured with a portable stadiometer (Seca Gmbh \& Co. KG, Hamburg, Germany) with an accuracy of $0.1 \mathrm{~mm}$

Table 1. Anthropometric and physical characteristics of the sample studied.

\begin{tabular}{|c|c|c|c|c|c|c|c|}
\hline \multirow{2}{*}{ Variables } & \multicolumn{2}{|c|}{ Males } & \multicolumn{2}{|c|}{ Females } & \multirow[t]{2}{*}{$\mathrm{p}$} & \multicolumn{2}{|c|}{ Totals } \\
\hline & $\mathrm{X}$ & SD & $\mathrm{X}$ & SD & & $\mathrm{X}$ & SD \\
\hline Age (years) & 19.7 & 1.8 & 19.6 & 1.3 & 0.2945 & 19.6 & 1.7 \\
\hline Weight (kg) & 70.9 & 10.8 & $58.7^{*}$ & 9.5 & $<0.0001$ & 67.0 & 11.8 \\
\hline Height (cm) & 172.8 & 7.8 & $159.4 *$ & 6.0 & $<0.0001$ & 168.6 & 9.6 \\
\hline Sitting height $(\mathrm{cm})$ & 91.8 & 3.8 & $84.9 *$ & 3.0 & $<0.0001$ & 89.6 & 4.8 \\
\hline \multicolumn{8}{|l|}{ Body Adiposity } \\
\hline WC (cm) & 75.9 & 8.5 & $68.1^{*}$ & 8.6 & $<0.0001$ & 73.4 & 9.3 \\
\hline BMI $\left(\mathrm{kg} / \mathrm{m}^{2}\right)$ & 23.7 & 3.2 & 23.1 & 3.3 & 0.3665 & 23.5 & 3.2 \\
\hline \multicolumn{8}{|l|}{$\Sigma$ Skinfolds (mm) } \\
\hline Arm skinfolds & 20.0 & 5.0 & $29.0^{*}$ & 6.0 & $<0.0001$ & 23.0 & 7.0 \\
\hline Trunk skinfolds & 72.0 & 21.2 & $80.6^{*}$ & 16.3 & 0.0360 & 74.7 & 20.1 \\
\hline Leg skinfolds & 24.5 & 6.1 & $29.8^{*}$ & 6.0 & $<0.0001$ & 26.2 & 6.6 \\
\hline Total skinfolds & 116.9 & 30.1 & 139.8* & 23.5 & 0.0001 & 124.2 & 30.0 \\
\hline \multicolumn{8}{|l|}{ Aerobic capacity } \\
\hline N. distance (m) & 1511.3 & 408.2 & $941.9 *$ & 359.2 & $<0.0001$ & 1331.2 & 473.4 \\
\hline $\mathrm{N} . \mathrm{VO}_{2 \max }\left(\mathrm{ml} \cdot \mathrm{kg}^{-1} \cdot \mathrm{min}^{-1}\right)$ & 54.4 & 5.6 & $46.4^{*}$ & 5.7 & $<0.0001$ & 51.9 & 6.8 \\
\hline
\end{tabular}

Legend: H: Height, WC: Waist circumference, BMI: Body Mass Index, N: Navette, X: Average, SD: Standard deviation. 


\section{Body fat and aerobic capacity of physical education students}

Eur J Transl Myol 31 (4): 10031, 2021 doi: 10.4081/ejtm.2021.10031

based on the Frankfurt Plane. Sitting height (trunkcephalic height) was measured with the student sitting on a wooden bench $50 \mathrm{~cm}$ high. Waist circumference $(\mathrm{cm})$ was measured with a metal tape measure (Seca) graduated in millimeters with an accuracy of $0.1 \mathrm{~cm}$. Seven skinfolds on the right side of the body were measured (mm): triceps and bicep (arm), subscapularis, iliac crest and abdominal (trunk), and thigh and calf (leg). A Harpenden skinfold caliper (Made in England), with a constant pressure of $10 \mathrm{~g} / \mathrm{mm}^{2}$, was used. Body Mass Index (BMI) was calculated by using the formula BMI = Weight $(\mathrm{kg}) /$ height $^{2}(\mathrm{~m})$. To estimate aerobic capacity, the 20-meter out-and-back running test proposed by Leger et al. ${ }^{12}$ (Navette field test) was used. Prior to the tests, students engaged in a (10 minute) warm up where they performed joint mobility exercises and jogging. The test consisted of a 20 meter back and forth run (starting with a speed of $0.5 \mathrm{~km} \cdot \mathrm{h}^{-1}$ and increasing the speed each minute). Students performed the test in a closed sports gymnasium where they were evaluated. The test was stopped when the subject could not reach the beep sound during the test in two consecutive attempts. The equation used to calculate speed was the following:

[Y= -27.4+6.0*MAV(12)]

where MAV $=$ Maximum Aerobic Velocity, $\mathrm{Y}=\mathrm{VO}_{2 \max }$, and predicted (ml.kg-1. $\left.\mathrm{min}^{-1}\right)$. In addition, the distance was measured and recorded for each subject completing the test.

Normality of the data was determined with the Kolmogorov-Smirnov test. Afterwards, data was analyzed using descriptive statistics, arithmetic mean, standard deviation, and range. Differences between males and females were calculated by using the t-test for independent samples. The relationship between the $\mathrm{VO}_{2 \text { máx }}$ and distance run with the body adiposity indicators were carried out by means of Pearson's correlation coefficient. In addition, the simple linear regression was performed in steps to determine \% of explanation. The $\mathrm{R}^{2}$ (adjusted), Standard Estimation Error (SEE), and probability were calculated. The aerobic capacity performance was divided into three categories. Tertiles (<p33: low, p33 to p66: moderate, and >p66: high) were used. One way Anova and Tukey's specificity test were used to determine differences between the categories. For all cases, a probability of $\mathrm{p}<0.05$ was adopted. Statistical analysis was carried out using SPSS v.18.0.

\section{Results}

Table 1 illustrates the anthropometric characteristics and the aerobic capacity of the sample of university students. Males showed greater weight, height, sitting height, WC, and aerobic endurance (meters and $\mathrm{VO}_{2 \max }$ ) than did the females $(p<0.05)$. Females had greater body adiposity for the arms, trunk, legs, and the total of the 7 skinfolds $(p<0.05)$. No significant difference occurred in age or BMI for both sexes.

The correlations between the adiposity indicators, age, and aerobic capacity are illustrated in Table 2. Negative correlations occurred between the body adiposity indicators and the aerobic capacity in both sexes. For the males, the correlations varied from $r=-0.37$ to -0.53 and for the females from $r=-0.21$ to 0.34 . In general, the most body fat (BMI, WC, and 7 skinfolds) occurred in males (R2= 14 to $27 \%$ ). However, for the females, the $\Sigma 7$ skinfolds only explained $11 \%$ of body adiposity.

Comparisons between the aerobic capacity categories are shown in Table 3. Significant differences occurred between male subjects in the low category with subjects in the moderate and high categories. This was observed in all of the adiposity indicators except for the BMI where no significant differences occurred between the moderate

Table 2. Relationship between aerobic capacity and body adiposity indicators.

\begin{tabular}{|c|c|c|c|c|c|c|c|c|c|}
\hline \multirow{2}{*}{ Variable Dependent } & \multirow{2}{*}{$\begin{array}{c}\text { Variable } \\
\text { Independent }\end{array}$} & \multicolumn{4}{|c|}{ Males } & \multicolumn{4}{|c|}{ Females } \\
\hline & & $\mathrm{R}$ & $\mathrm{R}^{2}$ & SEE & $\mathrm{P}$ & $\mathrm{R}$ & $\mathrm{R}^{2}$ & SEE & $\mathrm{P}$ \\
\hline \multirow{7}{*}{ Aerobic capacity (m) } & Age & -0.10 & 0.01 & 4.09 & 0.001 & -0.085 & 0.007 & 3.600 & 0.164 \\
\hline & WC & -0.41 & 0.17 & 3.75 & 0.000 & -0.287 & 0.082 & 3.500 & 0.001 \\
\hline & BMI & -0.43 & 0.19 & 3.71 & 0.000 & -0.217 & 0.047 & 3.500 & 0.002 \\
\hline & $\Sigma$ arm & -0.46 & 0.21 & 3.64 & 0.000 & -0.281 & 0.079 & 3.500 & 0.000 \\
\hline & $\Sigma$ trunk & -0.52 & 0.27 & 3.50 & 0.000 & -0.283 & 0.080 & 3.500 & 0.000 \\
\hline & $\Sigma$ legs & -0.37 & 0.14 & 3.80 & 0.000 & -0.282 & 0.080 & 3.500 & 0.000 \\
\hline & $\Sigma 7$ skinfolds & -0.52 & 0.27 & 3.50 & 0.000 & -0.340 & 0.115 & 3.400 & 0.000 \\
\hline \multirow{7}{*}{ Aerobic capacity $\left(\mathrm{VO}_{2 \text { máx }}\right)$} & Age & -0.07 & 0.01 & 5.63 & 0.000 & -0.111 & 0.012 & 5.800 & 0.001 \\
\hline & WC & -0.37 & 0.14 & 5.24 & 0.000 & -0.329 & 0.108 & 5.510 & 0.000 \\
\hline & BMI & -0.42 & 0.18 & 5.13 & 0.000 & -0.219 & 0.048 & 5.690 & 0.000 \\
\hline & $\Sigma$ arm & -0.47 & 0.22 & 4.98 & 0.000 & -0.288 & 0.083 & 5.590 & 0.000 \\
\hline & $\Sigma$ trunk & -0.52 & 0.27 & 4.83 & 0.000 & -0.289 & 0.084 & 5.580 & 0.000 \\
\hline & $\Sigma$ legs & -0.39 & 0.15 & 5.20 & 0.000 & -0.272 & 0.074 & 5.610 & 0.000 \\
\hline & $\Sigma 7$ skinfolds & -0.53 & 0.28 & 4.80 & 0.000 & -0.343 & 0.118 & 5.480 & 0.000 \\
\hline
\end{tabular}

Legend: H: Height, WC. Waist circumference, BMI. Body Mass Index, N: Navette, SEE: Standard estimation error, P: Probability. 
Body fat and aerobic capacity of physical education students

Eur J Transl Myol 31 (4): 10031, 2021 doi: 10.4081/ejtm.2021.10031

Table 3. Relationship between aerobic capacity and body adiposity indicators.

\begin{tabular}{|c|c|c|c|c|c|c|c|c|c|c|c|c|}
\hline \multirow{3}{*}{$\begin{array}{l}\text { Indicators } \\
\text { adiposity }\end{array}$} & \multicolumn{6}{|c|}{ Males } & \multicolumn{4}{|c|}{ Females } & \multirow{2}{*}{\multicolumn{2}{|c|}{ High }} \\
\hline & \multicolumn{2}{|c|}{ Low } & \multicolumn{2}{|c|}{ Medium } & \multicolumn{2}{|c|}{ High } & \multicolumn{2}{|c|}{ Low } & \multicolumn{2}{|c|}{ Medium } & & \\
\hline & $\mathrm{X}$ & SD & $\mathrm{X}$ & SD & $\mathrm{X}$ & SD & $\mathrm{X}$ & SD & $\mathrm{X}$ & SD & $\mathrm{X}$ & SD \\
\hline WC (cm) & 81.1ab & 10.6 & $75.1 b$ & 8.1 & 72.6 & 6.4 & 66.8ab & 8.0 & 72.3 & 10.5 & 63.3 & 5.0 \\
\hline BMI $\left(\mathrm{kg} / \mathrm{m}^{2}\right)$ & $26.2 \mathrm{ab}$ & 3.1 & 23.2 & 3.2 & 22.6 & 2.7 & 22.4 & 4.7 & 24.3 & 2.9 & 22.1 & 2.4 \\
\hline$\Sigma$ P. arm & $24.4 \mathrm{ab}$ & 5.2 & $20.4 b$ & 4.8 & 17.0 & 5.5 & 30.0 & 9.0 & 30.0 & 4.0 & 28.0 & 3.0 \\
\hline$\Sigma$ P. trunk & $88.6 \mathrm{ab}$ & 17.9 & $71.0 \mathrm{~b}$ & 17.8 & 58.1 & 24.1 & 83.4ab & 21.8 & 81.8 & 14.7 & 77.2 & 12.8 \\
\hline$\Sigma$ P. legs & $27.6 \mathrm{ab}$ & 2.6 & $25.2 b$ & 6.6 & 21.1 & 6.7 & 31.6ab & 7.0 & 29.4 & 5.6 & 28.3 & 6.3 \\
\hline$\Sigma 7$ skinfolds & $140.6 \mathrm{ab}$ & 23.4 & 116.6b & 26.2 & 96.2 & 33.8 & 145.3ab & 33.4 & 140.9 & 17.7 & 133.7 & 18.2 \\
\hline
\end{tabular}

Legend: $5:$ Sum of skinfolds, WC: Waist circumference, BMI: Body Mass Index, X: Average, SD: Standard deviation, a: Significant difference related to a median, $b$ : Significant difference related to high.

and high categories ( $p>0.05)$. For the females, significant differences emerged between the low and moderate categories as well as between the low and high categories $(\mathrm{p}<0.05)$. Differences also occurred in the WC and the skinfolds of the trunk, legs, and the $\Sigma 7$ skinfolds $(p<0.05)$. No differences were observed in the BMI between the three categories.

\section{Discussion}

The results from this study demonstrated moderate negative correlations between the body adiposity indicators and the aerobic capacity of the university students from the physical education program. The \% of the variance was higher in the males than the females, especially in the sum of the 7 skinfolds that explained $27 \%$ in males and $11 \%$ in females. These findings are consistent with other studies carried out on young university students. Regardless of the university program where it was reported, levels of physical fitness were related inversely with BMI and \% of body fat, especially with the aerobic capacity. ${ }^{10,13}$ In fact the results obtained from this research reinforce the changes that have been occurring for a number of years. These changes include an accelerated increase in body adiposity in university students. ${ }^{3}$ On the other hand, physical fitness, in general, has been decreasing throughout the years while body adiposity has been increasing rapidly in the past decades. ${ }^{14}$ This suggests that with the passage of time, these young university students will probably experience a more sedentary and deteriorating lifestyle. However, in general, these physical education students engaged in more regular physical activities. These activities should help maintain and/or increase their cardio pulmonary and musculoskeletal capacity and attain optimal \% levels of body fat. Although it seems that higher levels of aerobic physical activity are necessary, as this may help to reflect better levels of body adiposity and may even be the basis for reducing obesity and at the same time the beginning of behavioral change among the young people studied.
This level of fitness is important for developing adequate physical activities during professional exercise. In fact, for almost 20 years it has been suggested that physical education students should pass a physical fitness test before graduation, ${ }^{15,16}$ which could help to reflect an adequate anthropometric and physical profile not only personally, but also for their own students. For these types of populations, this may guarantee increased labor productivity, satisfaction, and psychological well-being for employees as they perform their jobs. ${ }^{17}$ In general, higher education students, independent of the type of professional program, need to reach acceptable levels of aerobic fitness. Reaching these levels is necessary since they facilitate carrying out prolonged daily work and physical exercise activities without individuals experiencing fatigue. ${ }^{18}$ In essence, maintaining and/or improving the cardio-pulmonary and musculoskeletal system levels promote acceptable physical performance, not only for sports, but also for work performance. ${ }^{10}$ However, as time passes, fat mass, bone mass, and lean mass may undergo negative changes with time if they do not maintain a healthy lifestyle. Consequently, students from the health professions need to understand nutritional and physical activity information in order to help prevent chronic degenerative diseases in individuals. ${ }^{19}$ This knowledge is especially important for physical education students, particularly where, in the future, they may encounter these types of ailments when they are working in schools. Therefore, it is important for future physical education teachers to not only maintain acceptable aerobic fitness, but also a healthy and fit body. This study had some limitations that future researchers need to take into consideration. For example, a sophisticated instrument was not used to measure the body composition of the physical education students in the laboratory. This might have biased measurements when using the anthropometric technique. Additionally, the small number of students in the sample did not allow 


\section{Body fat and aerobic capacity of physical education students}

Eur J Transl Myol 31 (4): 10031, 2021 doi: 10.4081/ejtm.2021.10031

generalization since it was not possible to select the sample size probabilistically. As a result, these findings must be viewed with caution. The conclusion drawn from this study is that body adiposity expressed in terms of WC, BMI, and skinfolds to a greater extent limits the aerobic capacity in males. However, in females, the sum of the 7 skinfolds affects to a lesser extent aerobic capacity. In general, for both sexes, students classified as having a higher aerobic capacity presented less body fat than their counterparts classified as moderate and low levels of aerobic capacity. The results suggest that the physical education students studied, in spite of presenting normal body weight for age and sex, need to take precautions for reducing their levels of body adiposity.

\section{List of acronyms}

BMI - Body Mass Index

MAV = Maximum Aerobic Velocity

SEE - Standard Estimation Error

$\mathrm{VO}_{2 \max }$ - Maximum oxygen consumption

WC - waist circumference

WHO - World Health Organization

$\Sigma 7$ skinfold - Sum of skin folds

\section{Authors' contributions}

MCB, RGC: conception, design, drafting of the manuscript, analysis and interpretation of the data, critical review and final approval of the version to be published, agreement to be responsible for all aspects of the work to ensure that issues related to the accuracy or completeness of any part of the work are adequately investigated and resolved; MCB, RGC, JMC, JFL: critical review of important intellectual content; and final approval of the version to be published; JMC, RVE, GHC, CUA: Data collection, formal data analysis and final approval.

\section{Acknowledgments}

A special recognition of thanks to the university athletes.

\section{Funding}

This research did not receive any specific grant from funding agencies in the public, commercial, or notfor-profit sectors

\section{Conflict of Interest}

The authors declare no competing interests

\section{Ethical Publication Statement}

We confirm that we have read the Journal's position on issues involved in ethical publication and affirm that this report is consistent with those guidelines.

\section{Corresponding Author}

Rossana Gomez Campos, PhD, Av San Miguel s/n Talca, Chile.

ORCID iD: 0000-0001-6509-570

E-mail: rossaunicamp@gmail.com
E-mails and ORCID iD of co-authors

Jorge Mendez-Cornejo: jmendez@ucm.cl ORCID iD: 0000-0002-3925-170X

Ruben Vidal Espinoza: rvidal@gmail.com

ORCID iD: 0000-0002-8593-5248

Gernot Hecht Chau: gernot.hecht@usm.cl

ORCID iD: 0000-0002-8880-5190

Camilo Urra Albornoz: c.urra.albornoz@gmail.com

ORCID iD: 0000-0002-5936-359X

Marco Cossio-Bolaños: mcossio1972@hotmail.com

ORCID iD: 0000-0001-7230-9996

\section{References}

1. Moreno GM. Definición y clasificación de la obesidad. Revista Médica Clínica Las Condes. 2012; 23(2): 124-128. doi: 10.1016/S07168640(12)70288-2.

2. Organización Mundial de la Salud. Obesidad y sobrepeso. Recuperado 15 julio, 2018. http://www.who.int/es/news-room/factsheets/detail/obesity-and-overweight.

3. Contreras Mellado V, Vilchez Avaca C, GómezCampos R, Luarte Rocha C, Cossio-Bolaños M. Tendencias al incremento de la adiposidad corporal y la presión arterial dejóvenes universitarios en dos cohortes (2009-2014). Nutr Hosp. 2015; 32(6): 2551-2558. doi: 10.3305/nh.2015.32.6.9784.

4. Ortega FB, Ruiz JR, Castillo MJ, Sjöström M. Physical fitness in childhood and adolescence: a powerful marker of health. Int J Obes (Lond). 2008; 32:1-11. doi: 10.1038/sj.ijo.0803774

5. Moliner-Urdiales D, Ortega F, Vicente-Rodriguez G, Rey-Lopez JP, Gracia-Marco L, Widhalm K, Sjöström M, Moreno LA, Castillo MJ, Ruiz JR. Association of physical activity with muscular strength and fat-free mass in adolescents: the HELENA study. Eur J Appl Physiol. 2010; 109: 1119e1127. doi: 10.1007/s00421-010-1457-z

6. Gu X, Chang M, Solmon M. Physical activity, physicalfitness, and health-relatedquality of life in school-aged children. J Teach Phys Educ. 2016; 35:117e126. doi: 10.1123/jtpe.2015-0110

7. Lema L, Mantilla SC, Arango CM. Asociación entre condición física y adiposidad en escolares de montería, Colombia. Revista Internacional de Medicina y Ciencias de la Actividad Física y del Deporte. 2016; 16(62): 277-296. doi: 10.15366/rimcafd2016.62.007

8. Valero G, Zurita Ortega F, San Román Mata S, Pérez Cortés J, Puertas Molero P, Chacón Cuberos R. Análisis de la capacidad aeróbica como cualidad esencial de la condición física de los estudiantes: Una revisión sistemática. Retos. 2018; 34: 395-402. doi: 10.47197/retos.v0i34.58278

9. Minasian V, Marandi SM, Kelishadi R, Abolhassani H. Correlation between Aerobic Fitness and Body Composition in Middle School Students. Int J Prev Med. 2014; 5(Suppl 2): S102- 


\section{Body fat and aerobic capacity of physical education students}

Eur J Transl Myol 31 (4): 10031, 2021 doi: 10.4081/ejtm.2021.10031

S107. Minasian V, Marandi SM, Kelishadi R, Abolhassani H. Correlation between Aerobic Fitness and Body Composition in Middle School Students. Int J Prev Med. 2014 Dec;5(Suppl 2):S102-7. doi: 10.4103/2008-7802.157666.

10. Kumar A, Kumar M. Effect of Body Composition and Aerobic Capacity on Blood Pressure in Young Indian Adult Males of Age Group 18-21 Years. International Journal of Science and Research (IJSR). 2015; 4 (10): 816-820.

11. Ross WD, Marfell-Jones M. Kinanthropometry. En: Physiological testing of the highperformance athlete. Champaign, Ill: Human Kinetic.1998; p.223-308.

12. Leger LA, Mercier D, Gadoury C , Lambert J. The multistage 20 metre shuttle run test for aerobic fitness. J Sports Sci 1988; 6: 93 - 101. doi: 10.1080/02640418808729800

13. Razak M, Maizi I, Muhamad TA. Physical Activity, Aerobic Fitness and Body Composition among Students in Malaysia and Libya. Asian Social Science 2013; 9(16): 168-175. doi: 10.5539/ass.v9n16p168

14. Hayes L, White M, Unwin N, Bhopal R, Fischbacher C, Harland J, Alberti KG. Patterns of physical activity and relationship with risk markers for cardiovascular disease and diabetes in Indian, Pakistani, Bangladeshi and European adults in a UK population. J Public Health Med. 2002 Sep;24(3):170-8. doi: 10.1093/pubmed/24.3.170.

15. Fischbacher C, Harland J, Alberti KG. Patterns of physical activity and relationship with risk markers for cardiovascular disease and diabetes in Indian, Pakistani, Bangladeshi and European adults in a UK population. J Public Health Med. 2002 Sep;24(3):170-8. doi: 10.1093/pubmed/24.3.170.

16. Petersen S, Byrne H, Cruz L. The Reality of Fitness for Pre-service Teachers: What Physical Education Majors "Know and Can Do". Kinesiology, Sport Studies and Physical Education Faculty Publications. 2003; 67. https://digitalcommons. rockport.edu/pes_facpub/67

17. De Miguel Calvo JM, Schweiger I, de las Mozas Majano O, Hernandez-Lopez J. Efecto del ejercicio físico en la productividad laboral y el bienestar. Revista de Psicología del Deporte. 2011; 20(2): 589-604.

18. Amani AR, Somchit MN, Konting MMB, Kok LY. Relationship between Body Fat Percent and Maximal Oxygen Uptake among Young Adults. Journal of American Science 2010; 6(4): 1-4.

19. Enríquez D, Marcos-Pardo P, Martínez-Rodríguez A, Candia-Luján R, Carrasco Legleu C. Actividad física, ingesta alimentaria e indicadores antropométricos en estudiantes universitarios. Tecnociencia chihuahua. 2017; 11(2):58-68.

Submission: August 12, 2021

Revision submitted: September 9, 2021 Accepted for publication: September 12, 2021 